\title{
Analisa Beban Kerja Fisik yang Dialami Pekerja pada Stasiun Pencetakan Worm Screw dengan Menggunakan Work Sampling (Studi Kasus : PT. Riau Logam Engineering)
}

\author{
Nofirza $^{1}$, Rahmat Syahputra ${ }^{2}$ \\ ${ }^{1,2}$ Jurusan Teknik Industri Fakultas Sains dan Teknologi, UIN Sultan Syarif Kasim Riau \\ Jl. HR. Subrantas No. 155 Simpang Baru, Pekanbaru, 28293 \\ Email: nofirza@uin-suska.ac.id, syahrahman35@gmail.com
}

\begin{abstract}
ABSTRAK
Manusia merupakan salah satu faktor utama dalam menjamin kelancaran proses produksi dalam industri. Ketersediaan tenaga kerja dengan tingkat keterampilan yang memadai dalam jumlah yang tepat merupakan salah satu kunci penting keberhasilan dalam mencapai pemenuhan permintaan dan target produksi. Tujuan dari penelitian ini adalah untuk mengetahui waktu baku dari proses pembuatan cetakan worm screw dengan mengunakan metode Work Sampling. Hasil pengukuran ini digunakan untuk menghitung beban kerja fisik yang dialami oleh operator pada saat bekerja. Berdasarkan hasil pengolahan data yang telah dilakukan pada penelitian ini maka diketahui waktu baku yang diperlukan oleh operator dalam menyelesaikan 1 unit cetakan worm screw adalah 20,5 menit dan beban kerja fisik yang diterima oleh operator pada stasiun pembuatan cetakan worm screw di PT. Riau Logam Engineering adalah $136 \%$ berada di range $>100 \%$ yang berarti bahwa beban kerja yang diterima oleh operator masih berada dalam kondisi berat. Usulan menambah 1 operator diharapkan dapat mengurangi beban kerja fisik yang diterima oleh operator atau berada pada range $<100 \%$ yang berarti bahwa beban kerja fisik yang diterima dalam kondisi ringan.
\end{abstract}

Kata kunci : Beban kerja fisik, Work Sampling

\section{Pendahuluan}

Dewasa ini, banyak perusahaan yang memberikan perhatian khusus pada efisiensi, efektifitas dan produktifitas. Karena dari ketiga hal tersebut, perusahaan dapat melihat penggunaan optimal dari sumber daya yang dimiliki serta pencapaiannya terhadap target yang diinginkan oleh suatu perusahan. Hal ini dapat dipenuhi apabila perusahan melakukan pengaturan terhadap jadwal penyelesaian permintaan dengan sebaik-baiknya. Salah satu faktor yang berpengaruh agar pesanan dapat diselesaikan atau terpenuhi sesuai dengan jadwal yang ditetapkan yaitu faktor waktu, pekerja atau tenaga kerja yang terlibat langsung didalam bagian proses produksi (Prabowo, 2010).

Peran pekerja sangat penting sebagai pengerakan aktivitas industri untuk dapat bersaing dan mempertahankan keunggulan produknya., sehingga perlu mendapat perhatian khusus terhadap operator yang bekerja karena operatorlah yang telah banyak meluangkan waktu, pikiran dan tenaga. Disamping itu operator yang bekerja juga memiliki perasaan, kebutuhan dan harapan-harapan yang dapat mempengaruhi kinerja pekerja, dedikasi, dan loyalitas, serta kecintaan terhadap pekerjaan dan industrinya (Umar, 2011).

PT. Riau Logam Engineering ( RLE) adalah Industri Manufaktur Nasional berpengalaman dalam bidang pengecoran logam besi dan baja serta permesinan beralokasi di Pekanbaru Provinsi Riau Indonesia. Perusahaan ini didirikan bertujuan untuk memenuhi kebutuhan industri-industri dalam negeri, yang selama ini sebagian dipasok dari luar negeri. Segmen industri yang akan dituju adalah industri kelapa sawit sebagai penghasil $\mathrm{CPO}$, industri kertas (pulp and papers), industri minyak bumi dan gas (Oil and Gas). Adapun produk yang dihasilkan adalah Worm Screw dan Sporket untuk industri kelapa sawit dan lainnya, untuk menghasilkan produk tersebut ada beberapa proses yang harus dilewati mulai dari 
perancangan desain produk, pembuatan cetakan, peleburan biji besi dan proses akhir adalah permesinan.

Stasiun pembuatan cetakan merupakan proses yang sangat vital, karena pada stasiun ini masih mengandalkan manusia sebagai pekerja mulai dari tahap awal hingga tahap akhir. Pada stasiun kerja ini terdapat 2 orang pekerja dimana selama jam kerja terdapat kegiatan-kegitan yang sangat menguras tenaga, seperti memindahkan flash box, memadatkan pasir, melepaskan mall dan memberi cairan dempul keseluruh lubang mall. Ditambah lagi target produksi yang diharus diselesaikan adalah 20 buah worm screw per hari, yang selalu tidak tercapai.

Tabel 1. Data Produksi bulan Oktober 2015

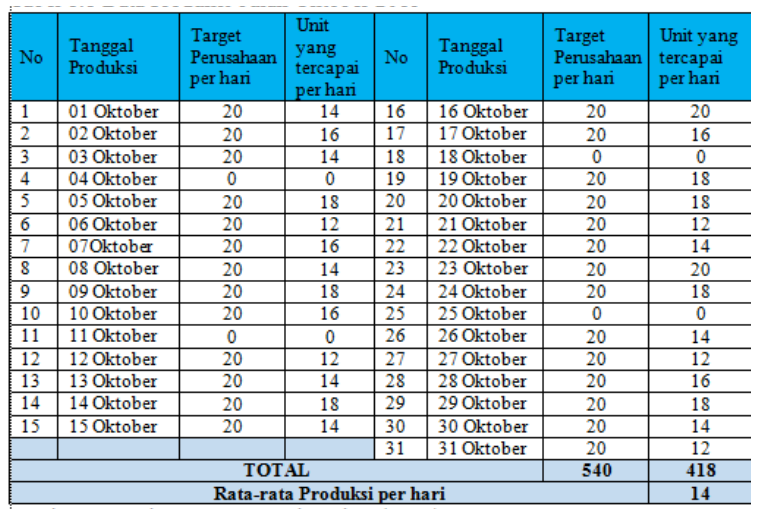

Sumber : PT. Riau Logam Enggineering (2015)

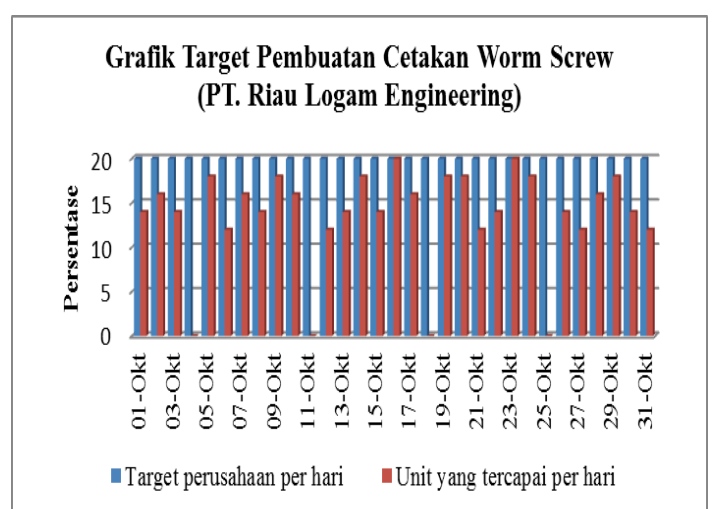

Gambar 1. Grafik Target Pembuatan Cetakan Worm Screw

Dapat dilihat dari rekapitulasi tabel dan grafik diatas bahwa rata-rata target produksi per hari masih belum tercapai, yang mana selama satu bulan seharusnya perusahaan memproduksi worm screw sebanyak 540. Namun pada kenyataan, perusahaan hanya memproduksi 418 unit worm screw. Perusahaan hanya mencapai target pada tanggal 16 dan 23. Selebihnya pekerja dilapangan tidak mencapai target pembuatan worm screw yang ditetapkan oleh perusahaan, disebabkan karena banyaknya waktu menganggur dan beban kerja yang dialami oleh pekerja. Beban kerja yang terjadi karena peralatan kerja yang terlalu berat dan tempat kerja yang tidak nyaman. Tidak tercapainya ratarata target produksi per hari ini juga menyebabkan beban mental pada pekerja selain kelelahan akibat bekerja.

Pekerja pada stasiun pencetakan worm screw ini pada saat bekerja mereka harus memindahkan flash box worm screw secara manual dan dapat dilihat dari gambar 1.2 bahwa ukuran flash box worm screw adalah $150 \mathrm{~cm} \times$ $50 \mathrm{~cm}$ dan berbahan besi yang memiliki berat \pm $30 \mathrm{~kg}$.

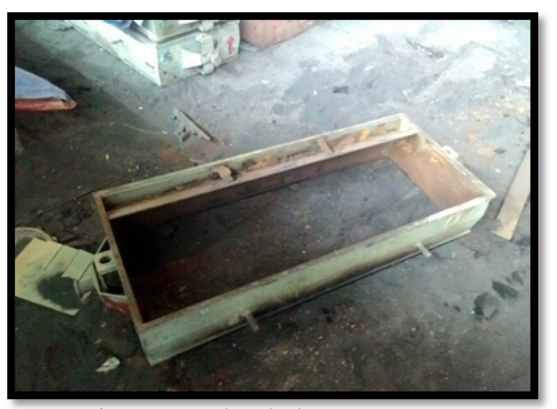

Gambar 2. Flash box worm screw

Berdasarkan wawancara dengan manajer produksi, diketahui target produksi merupakan hal terpenting dalam perusahaan yang harus dipenuhi untuk memberikan keuntungan. Sebelumnya perusahaan telah melakukan alternatif dalam mencapai target produksi yaitu dengan memberikan jam tambah untuk proses produksi (waktu lembur) namun perusahaan tidak selamanya bisa melakukan alternatif ini disebabkan akan mengeluarkan banyak biaya tambahan dan juga akan memberikan dampak negatif pada kesehatan pekerja distasiun pembuatan cetakan worm screw ini.

Untuk mendapatkan keuntungan manajer produksi harus memperhatikan jumlah operator yang optimal pada stasiun pencetakan ini agar tercapainya target produksi dan mendapatkan keuntungan.

Maka dari itu perlu dilakukan pengukuran waktu untuk mengetahui waktu baku dari proses pembuatan cetakan worm screw dengan mengunakan metode Work sampling. Dari hasil pengukuran akan diperoleh waktu baku untuk menyelesaikan pembuatan cetakan worm screw, dimana data sampling ini bisa digunakan untuk perhitungan beban kerja yang diterima oleh operator pada saat bekerja. Dari hasil sampling ini diharapkan diketahui permasalahan dan bagaimana mengatasi hal tersebut sehingga diketahui seberapa produktif operator dalam melakukan pekerjaanya dan 
tingkat beban kerja fisik yang diterima oleh operator pada saat bekerja.

\section{Metode Penelitian}

Dalam melaksanakan sebuah penelitian terdapat tahap-tahap yang harus dilalui, tahaptahap dalam penelitian ini dapat dilihat pada gambar 3.1.

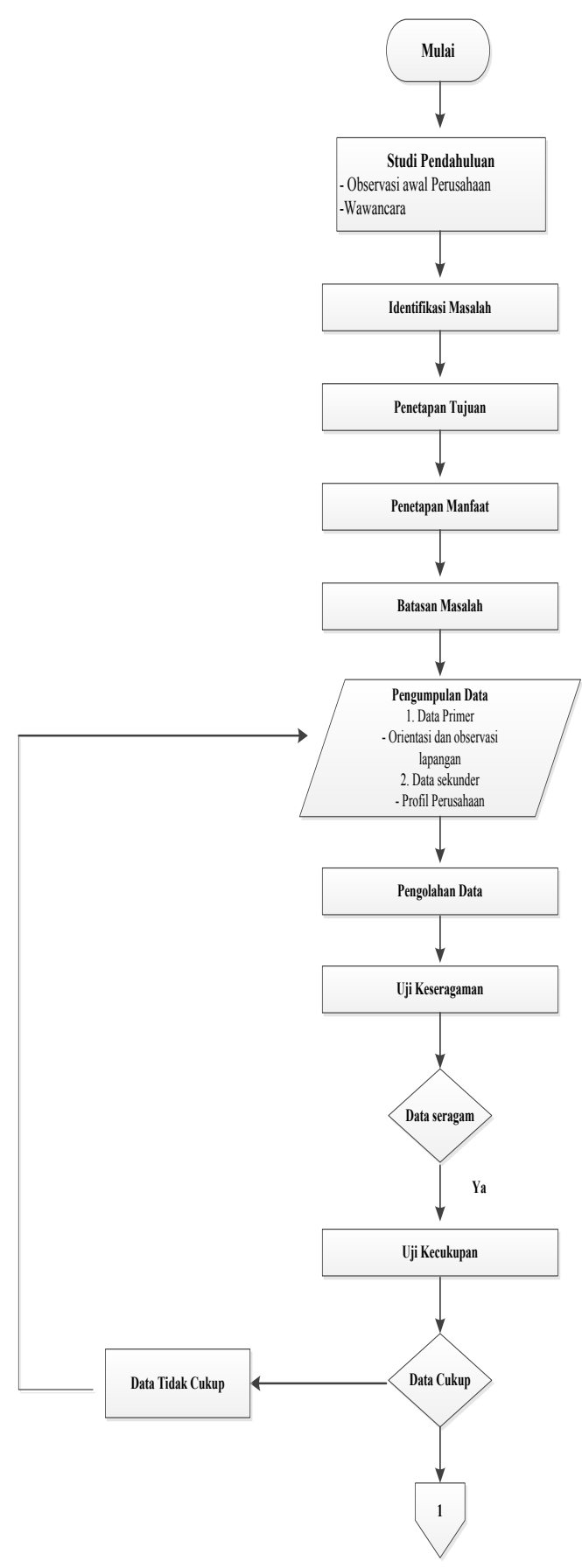

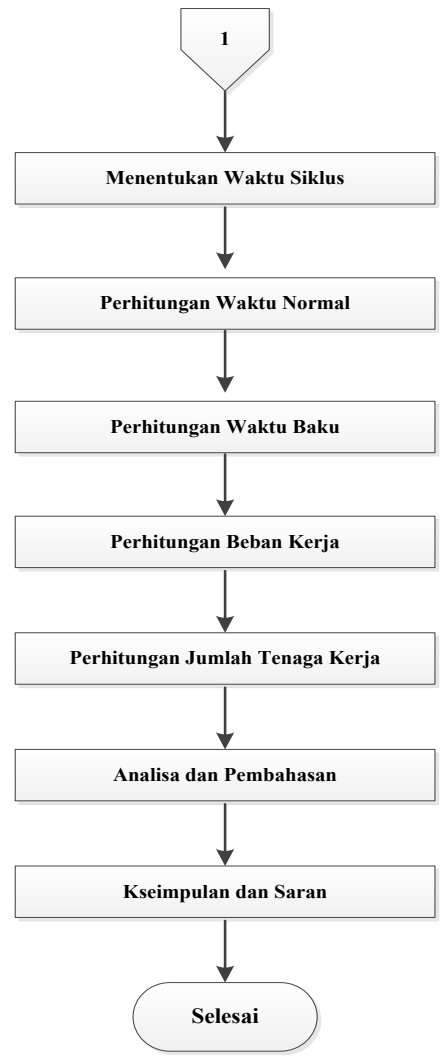

Gambar 3. Flowchart Tahapan Penelitian

Pada penelitian ini data yang digunakan adalah data primer dan data sekunder.

1. Data Primer

Adapun data primer yang digunakan dalam penelitian ini diperoleh dari hasil :

a. Wawancara mengenai kondisi kerja operator stasiun pembuatan cetakan worm screw.

b. Hasil pengamatan langsung aktifitas operator dengan metode work sampling

2. Data sekunder

Data sekunder yang digunakan dalam penelitian ini diperoleh dari hasil :

a. Profil perusahaan PT. Riau Logam Engineering

b. Sejarah Perusahaan PT. Riau Logam Engineering

Data aktifitas operator yang dikumpulkan kemudian diolah dengan menggunakan metode work sampling, dimana terdapat tahap-tahap yang harus dilewati antara lain sebagai berikut:

1. Menentukan elemen pekerjaan produktif dan non produktif

2. Penentuan jadwal kunjungan, dimana peneliti menggunakan interval 5 menit selama pengamatan dengan jam kerja selama 7 jam. 
3. Perhitungan uji keseragaman, uji kecukupan, menghitung waktu siklus, waktu normal, waktu baku, dan menghitung beban kerja serta menghitung jumlah tenaga kerja.

\section{Hasil dan Pembahasan}

\section{Elemen Pekerjaan Produktif dan Non- Produktif}

Berdasarkan pengamatan yang dilakukan di PT. Riau Logam Engineering pada stasiun pembuatan worm screw terdapat dua orang operator yang bekerja dalam satu stasiun dengan elemen pekerjaan yang sama. Maka peneliti hanya mengambil satu operator saja yaitu Operator Adin untuk mewakili pengamatan, selanjutnya diperoleh masing-masing elemen pekerjaan produktif dan non produktif dari operator dalam menyelesaikan pekerjaanya adalah sebagai berikut :

Tabel 2. Elemen Kerja Produktif dan Non Produktif

\begin{tabular}{|l|l|l|l|}
\hline $\begin{array}{c}\text { Elemen } \\
\text { Kerja } \\
\text { Produktif }\end{array}$ & Ket & $\begin{array}{c}\text { Elemen kerja } \\
\text { Non Produktif }\end{array}$ & Ket \\
\hline $\begin{array}{l}\text { Mengambil } \\
\text { flash box }\end{array}$ & 1 & Mengobrol & A \\
\hline $\begin{array}{l}\text { Memasukan } \\
\text { mall cetakan } \\
\text { kedalam flash } \\
\text { box }\end{array}$ & 2 & Duduk & $\mathrm{B}$ \\
\hline $\begin{array}{l}\text { Memasukan } \\
\text { pasir kedalam } \\
\text { flash box }\end{array}$ & 3 & $\begin{array}{l}\text { Ke kamar } \\
\text { mandi }\end{array}$ & $\mathrm{C}$ \\
\hline Melepas mall & 4 & Minum & $\mathrm{D}$ \\
\hline $\begin{array}{l}\text { Memberi } \\
\text { cairan dempul } \\
\text { pada lubang } \\
\text { cetakan }\end{array}$ & 5 & $\begin{array}{l}\text { Mengunaka } \\
\mathrm{n} \\
\text { handphone }\end{array}$ & $\mathrm{E}$ \\
\hline $\begin{array}{l}\text { Menyatukan } \\
\text { flash box } \\
\text { positif dan } \\
\text { negatif }\end{array}$ & 6 & Diam & $\mathrm{F}$ \\
\hline
\end{tabular}

\section{Penentuan Jadwal Kunjungan}

Waktu interval pengamatan ditetapkan selama 5 menit, dengan jam kerja selama 7 jam dimana dimulai dari jam 08.00 samapai dengan 16.00 dan jam istirahat dari jam 12.00 sampai dengan 13.00, untuk pengamatan selama 5 menit, banyakanya bilangan acak yang diperlukan untuk penjadwalan pengamatan selama waktu kerja dapat dilihat dari perhitungan berikut :

Banyaknya pengamatan

$$
\begin{aligned}
& =\frac{\text { Jumlah jam kerja per hari } \times 60 \text { menit }}{t} \\
& =\frac{7 \times 60 \text { menit }}{5} \\
& =84 \text { Bilangan acak }
\end{aligned}
$$

Jadi berdasarkan perhitungan di atas jumlah pengamatan tidak lebih dari 84 kali pengamatan dalam sehari. Berikut daftar bilangan acak yang terpilih:

Tabel 3. Bilangan Acak yang Terpilih

\begin{tabular}{|c|c|c|c|c|c|c|c|c|c|}
\hline \multicolumn{10}{|c|}{ Daftar Bilangan Acak Yang Terpilih } \\
\hline 2 & 5 & 9 & 12 & 15 & 19 & 20 & 22 & 27 & 30 \\
\hline 34 & 37 & 40 & 46 & 47 & 50 & 53 & 55 & 58 & 61 \\
\hline 62 & 66 & 74 & 77 & 81 & 83 & \multicolumn{1}{|c}{} \\
\hline
\end{tabular}

\section{Jadwal Kunjungan}

Jadual kunjungan kerja selama 7 jam kerja dengan lamanya waktu kunjungan selama 5 menit.

Tabel 3. Jadwal Kunjungan Work Sampling Hari $\mathrm{Ke}-1$

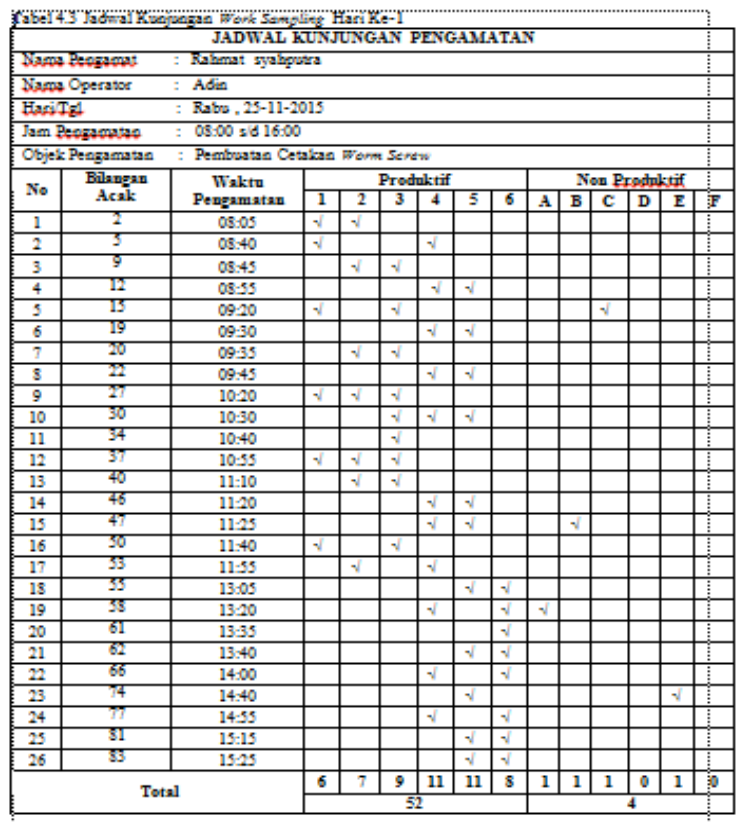

Tabel 4. Jadwal Kunjungan Work Sampling Hari $\mathrm{Ke}-2$

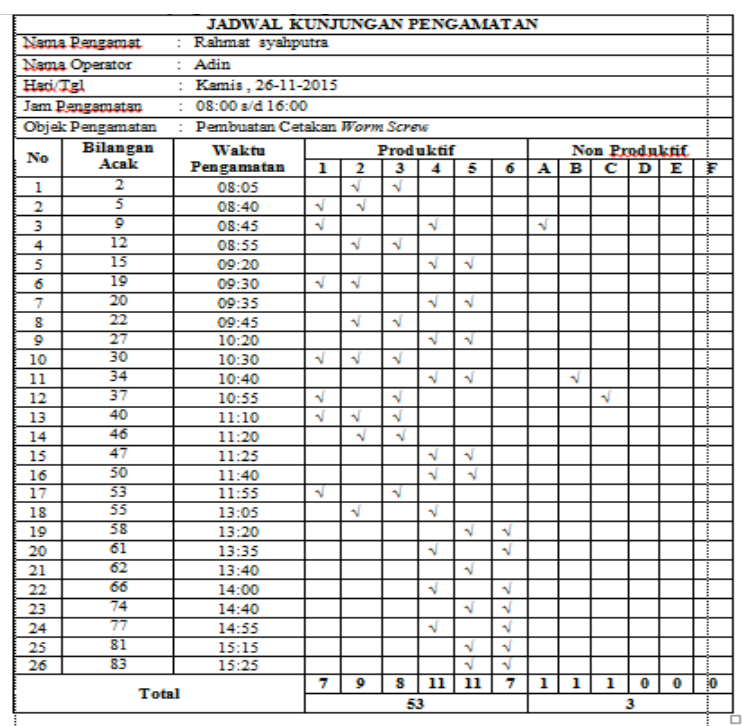


Tabel 5. Rakapitulasi Kerja Produktif dan Non Produktif

\begin{tabular}{|l|c|}
\hline \multicolumn{1}{|c|}{ Kegiatan } & Operator (Operator 1) \\
\hline Produktif & 105 \\
\hline Non Produktif & 7 \\
\hline Jumlah Pengamatan & 112 \\
\hline Total \% Produktif & $93 \%$ \\
\hline
\end{tabular}

\section{Pengolahan Data}

Pengolahan data merupakan bagian yang terpenting yang harus dilakukan, karena setelah data yang diinginkan sudah didapat maka tahap berikutnya ialah melakukan perhitungan dari data tersebut, dan berdasarkan hasil yang didapat maka didapatkan tujuan penilitian ini.

\section{Uji Keseragaman}

Uji keseragaman merupakan suatu uji untuk mengetahui apakah data yang telah dikumpulkan telah seragam atau belum. Keseragaman data ini dilihat dari tidak adanya data yang keluar dari batas bawah dan batas atas.

a. Menentukan batas kontrol

$$
\begin{aligned}
& \mathrm{BKA}=\overline{\mathrm{p}}+\mathrm{k} \sqrt{\frac{\overline{\mathrm{p}}(1-\overline{\mathrm{p}})}{\overline{\mathrm{n}}}} \\
& \mathrm{BKB}=\overline{\mathrm{p}}-\mathrm{k} \sqrt{\frac{\overline{\mathrm{p}}(1-\overline{\mathrm{p}})}{\overline{\mathrm{n}}}}
\end{aligned}
$$

b. Persen produktif hari 1 dan 2

$$
\begin{aligned}
& \mathrm{P}=\frac{\text { Jumlah Elemen Kerja Produktid }}{\text { Jumlah Pengamatan }} \times 100 \\
& \mathrm{P}_{1}=\frac{52}{56} \times 100=92 \% \quad \mathrm{P}_{2}=\frac{53}{56} \times 100=94 \% \\
& \overline{\mathrm{p}}=\frac{\sum \mathrm{Pi}}{\mathrm{k}} \quad=\frac{92+94}{2}=93 \%
\end{aligned}
$$

c. Jumlah pengamatan yang dilakukan $\overline{\mathrm{n}}=\frac{\sum \mathrm{p}_{\mathrm{i}}}{\mathrm{k}}=\frac{56+56}{2}=56$

d. Batas Kontrol

$$
\begin{aligned}
& \mathrm{BKA}=0,93+2 \sqrt{\frac{0,93(1-0,93)}{56}}=0,99 \\
& \mathrm{BKA}=0,93-2 \sqrt{\frac{0,93(1-0,93)}{56}}=0,87
\end{aligned}
$$

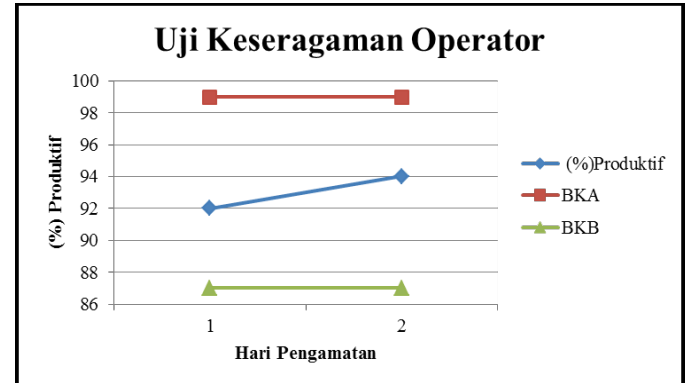

Gambar 4. Grafik uji keseragaman Data Operator (Operator 1)

Perhitungan uji keseragaman data ini bertujuan untuk melihat apakah data yang telah dikumpulkan berada dalam batas kontrol yang telah ditetapkan. Berdasarkan perhitungan uji keseragaman diproleh untuk operator batas kontrol atas (BKA) 99\% dan batas kontrol bawah (BKB) $87 \%$ dengan range data masih berada dalam batas kontrol dan dinyatakan data seragam. Ternyata semua harga-harga Pi berada dalam batas-batas ini sehingga semuanya dapat digunakan untuk menghitung banyaknya pengamatan yang diperlukan.

\section{Uji Kecukupan}

Uji kecukupan dilakuakn untuk memastikan apakah data yang digunakan ini telah cukup sebagai bahan penelitian. Uji kecukupan ini dilakukan dengan tingkat kepercayaan $95 \%$ dan keyakinan 5\%. Hal ini menunjukan bahwa dengan tingkat error sebesar $5 \%$ dan tingkat kepercayaan peneliti terhadap penelitiannya sebesar $95 \%$.

$$
\begin{aligned}
& \mathrm{P}=\frac{\text { Jumlah Elemen Kerja Produktif }}{\text { Jumlah Pengamatan }} \quad \mathrm{P}=\frac{105}{112} \quad \mathrm{P}=0,94 \\
& \mathrm{~N}^{\prime}=\frac{\left(\frac{2}{0,05}\right)^{2}(1-0,94)}{0,94}=\frac{1600(1-0,94)}{0,94}=102
\end{aligned}
$$

$$
\mathrm{N}^{\prime}=102 \text { ( Data yang dibutuhkan) }
$$$$
\mathrm{N}=112 \text { ( Data yang telah diukur) }
$$

Uji kecukupan data berguna untuk mengetahui data apakah sudah cukup untuk dilakukan pengolahan data atau belum. Untuk operator pada hari pertama data yang didapatkan adalah sebanyak 56 data dan 52 dari data tersebut adalah data produktif. Sehingga setelah dilakukan perhitungan uji kecukupan data, data dinyatakan belum mencukupi dan perlu melakukan pengamatan lagi. Hari kedua data yang didapatkan adalah sebanyak 56 data dan 53, setelah dilakukan uji kecukupan maka hasil yang didapat adalah untuk operator (Operator 1) $\mathrm{N}^{\prime}=$ 102 dan $\mathrm{N}=112$, dimana data yang dibutuhkan 
sebanyak 102 dan data yang telah diukur sebanyak 112. Jadi nilai $\mathrm{N}^{\prime}<\mathrm{N}$ maka data yang diukur telah cukup, dan tidak perlu adanya penambahan data lagi sehingga bisa dilanjutkan dengan perhitungan berikutnya.

\section{Persen Produktif Per Elemen Kerja}

Perhitungan ini dilakukan untuk melihat persen produktif per elemen kerja yang telah diamati.

a. Elemen Kerja 1

$$
\mathrm{Pi}=\frac{\mathrm{e}}{\mathrm{n}} \quad \mathrm{Pi}=\frac{13}{112} \quad \mathrm{Pi}=0,12
$$

b. Elemen Kerja 2

$$
\mathrm{Pi}=\frac{\mathrm{e}}{\mathrm{n}} \quad \mathrm{Pi}=\frac{16}{112} \quad \mathrm{Pi}=0,14
$$

c. Elemen Kerja 3

$$
\mathrm{Pi}=\frac{\mathrm{e}}{\mathrm{n}} \quad \mathrm{Pi}=\frac{17}{112} \quad \mathrm{Pi}=0,15
$$

d. Elemen Kerja 4

$$
\mathrm{Pi}=\frac{\mathrm{e}}{\mathrm{n}} \quad \mathrm{Pi}=\frac{22}{112} \quad \mathrm{Pi}=0,20
$$

e. Elemen Kerja 5

$$
\mathrm{Pi}=\frac{\mathrm{e}}{\mathrm{n}} \quad \mathrm{Pi}=\frac{22}{112} \quad \mathrm{Pi}=0,20
$$

f. Elemen Kerja 6

$$
\mathrm{Pi}=\frac{\mathrm{e}}{\mathrm{n}} \quad \mathrm{Pi}=\frac{15}{112} \quad \mathrm{Pi}=0,13
$$

Tabel 6. Rekapitulasi Persen Produktif Per Elemen Pekerjaan

\begin{tabular}{|l|c|}
\hline \multicolumn{2}{|c|}{ Persen Produktif Per Elemen Pekerjaan } \\
\hline $\begin{array}{c}\text { Elemen Pekerjaan } \\
\text { Operator (Operator 1) }\end{array}$ & $\begin{array}{c}\text { Operator (Operator } \\
\text { 1) }\end{array}$ \\
\hline Mengambil flash box & 0,12 \\
\hline $\begin{array}{l}\text { Memasukan mall cetakan } \\
\text { kedalam flash box }\end{array}$ & 0,14 \\
\hline $\begin{array}{l}\text { Memasukan pasir kedalam } \\
\text { flash box }\end{array}$ & 0,15 \\
\hline Melepas mall & 0,20 \\
\hline $\begin{array}{l}\text { Memberi cairan dempul pada } \\
\text { lubang mall }\end{array}$ & 0,20 \\
\hline $\begin{array}{l}\text { Menyatukan flash box positif } \\
\text { dan negatif }\end{array}$ & 0,13 \\
\hline
\end{tabular}

\section{Jumlah Menit Pengamatan}

PT. Riau Logam Engineering menerapkan jam kerja dari jam 08.00 sampai dengan 16.00 pegambilan data dilakukan selama 2 hari jam kerja dengan jumlah pengamatan sebanyak 26 kali pengamatan dalam interval waktu satu kali pengamatan selama 5 menit, sehingga total menit pengamatan ialah $2 \times 5 \times 26$ $=260$ menit.

a. Elemen Pekerjaan Produktif (1)

$\mathrm{Me}=\mathrm{Pi} \times$ Total Menit Pengamatan $=0,12 \times 260=30,2$ b. Elemen Pekerjaan Produktif (2)

$\mathrm{Me}=\mathrm{Pi} \times$ Total Menit Pengamatan

$$
=0,14 \times 260=37,1
$$

c. Elemen Pekerjaan Produktif (3) $\mathrm{Me}=\mathrm{Pi} \times$ Total Menit Pengamatan

$$
=0,15 \times 260=39,5
$$

d. Elemen Pekerjaan Produktif (4)

$\mathrm{Me}=\mathrm{Pi} \times$ Total Menit Pengamatan

$$
=0,20 \times 260=51,1
$$

e. Elemen Pekerjaan Produktif (5)

$\mathrm{Me}=\mathrm{Pi} \times$ Total Menit Pengamatan

$$
=0,20 \times 260=51,1
$$

f. Elemen Pekerjaan Produktif (6)

$\mathrm{Me}=\mathrm{Pi} \times$ Total Menit Pengamatan

$$
=0,13 \times 260=34,8
$$

Tabel 7. Rekapitulasi Menit Pengamatan Per Elemen Kerja

\begin{tabular}{|l|c|}
\hline \multicolumn{2}{|c|}{ Menit Pengamatan Per Elemen Kerja } \\
\hline \multicolumn{1}{|c|}{$\begin{array}{c}\text { Elemen Pekerjaan } \\
\text { Operator }\end{array}$} & $\begin{array}{c}\text { Operator (Operator 1) } \\
\text { (Menit) }\end{array}$ \\
\hline Mengambil flash box & 30,2 \\
\hline $\begin{array}{l}\text { Memasukan mall cetakan } \\
\text { kedalam flash box }\end{array}$ & 37,1 \\
\hline $\begin{array}{l}\text { Memasukan pasir kedalam } \\
\text { flash box }\end{array}$ & 39,5 \\
\hline Melepas mall & 51,1 \\
\hline $\begin{array}{l}\text { Memberi cairan dempul } \\
\text { pada lubang mall }\end{array}$ & 51,1 \\
\hline $\begin{array}{l}\text { Menyatukan flash box } \\
\text { positif dan negatif }\end{array}$ & 34,8 \\
\hline
\end{tabular}

\section{Waktu Siklus}

a. Elemen Pekerjaan Produktif (1) $\mathrm{WSU}=\frac{30,2}{13}=2,32$

b. Elemen Pekerjaan Produktif (2) $\mathrm{WSU}=\frac{37,1}{16}=2,32$

c. Elemen Pekerjaan Produktif (3) $\mathrm{WSU}=\frac{39,5}{17}=2,32$

d. Elemen Pekerjaan Produktif (4) $\mathrm{WSU}=\frac{51,1}{22}=2,32$

e. Elemen Pekerjaan Produktif (5) $\mathrm{WSU}=\frac{51,1}{22}=2,32$

f. Elemen Pekerjaan Produktif (6) $\mathrm{WSU}=\frac{34,9}{15}=2,32$

\section{Faktor Penyesuaian}

Perhitungan faktor penyesuaian ini mengunakan metode westinghouse yaitu dengan memberi nilai pada tingkat performance per elemen kerja produktif. 
Tabel 8. Rekapitulasi Waktu Siklus, Waktu Normal dan Waktu Baku

\begin{tabular}{|c|c|c|c|c|c|}
\hline \multicolumn{6}{|c|}{ Operator (Operator 1) } \\
\hline $\begin{array}{l}\text { Elemen } \\
\text { Pekerjaan }\end{array}$ & \begin{tabular}{|l} 
P \\
Penye- \\
suaian
\end{tabular} & $\begin{array}{c}\% \\
\text { Allo- } \\
\text { wance }\end{array}$ & $\begin{array}{c}\text { Ws - } \\
\text { Menit }\end{array}$ & $\begin{array}{l}\text { Wn- } \\
\text { Menit }\end{array}$ & $\begin{array}{l}\text { Wb- } \\
\text { Menit }\end{array}$ \\
\hline $\begin{array}{l}\text { Mengambil } \\
\text { flash box }\end{array}$ & 1,15 & 1,31 & 2,32 & 2,67 & 3,5 \\
\hline $\begin{array}{l}\text { Memasukan } \\
\text { mall cetakan } \\
\text { kedalam flash } \\
\text { box }\end{array}$ & 1,1 & 1,195 & 2,32 & 2,55 & 3,1 \\
\hline $\begin{array}{l}\text { Memasukan } \\
\text { pasir kedalam } \\
\text { flash box }\end{array}$ & 1,19 & 1,36 & 2,32 & 2,76 & 3,8 \\
\hline Melepas mall & 1,14 & 1,19 & 2,32 & 2,65 & 3,1 \\
\hline $\begin{array}{l}\text { Memberi cairan } \\
\text { dempul pada } \\
\text { lubang mall }\end{array}$ & 1,12 & 1,19 & 2,32 & 2,60 & 3,1 \\
\hline $\begin{array}{l}\text { Menyatukan } \\
\text { flash box positif } \\
\text { dan negatif }\end{array}$ & 1,16 & 1,46 & 2,32 & 2,69 & 3,9 \\
\hline \multicolumn{3}{|c|}{ Total } & 13,93 & 15,93 & 20,5 \\
\hline
\end{tabular}

Jadi waktu normal dalam menyelesaikan pekerjaan untuk Operator selama 15,93 Menit dan waktu baku untuk menyelesaikanpekerjaan ini adalah 20,5 Menit.

\section{Penentuan (Performance Rating) Penyesuaian dan (Allowance) Kelonggaran}

Performance rating bertujuan untuk memberi penilaian atau mengevaluasi kecepatan kerja seseorang operator, sedangkan allowance yaitu memberikan kelonggaran terhadap kegiatan yang tak terlelakan ketika bekerja. Penilaian performance rating dan allowance berdasarkan tabel Westinghouse System.

Tabel 10. Nilai Peformance Rating dan Allowance

\begin{tabular}{|c|l|c|c|}
\hline No & $\begin{array}{c}\text { Elemen } \\
\text { Pekerjaan }\end{array}$ & $\begin{array}{c}\text { Performance } \\
\text { Rating }\end{array}$ & Allowance \\
\hline 1 & $\begin{array}{l}\text { Mengambil flash } \\
\text { box }\end{array}$ & 1,15 & $1+31$ \\
\hline 2 & $\begin{array}{l}\text { Memasukan mall } \\
\text { cetakan kedalam } \\
\text { flash box }\end{array}$ & 1,1 & $1+19,5$ \\
\hline 3 & $\begin{array}{l}\text { Memasukan } \\
\text { pasir kedalam } \\
\text { flash box }\end{array}$ & 1,19 & $1+36$ \\
\hline 4 & Melepas mall & 1,14 & $1+19$ \\
\hline 5 & $\begin{array}{l}\text { Memberi cairan } \\
\text { dempul pada } \\
\text { lubang mall }\end{array}$ & 1,12 & $1+19$ \\
\hline 6 & $\begin{array}{l}\text { Menyatukan } \\
\text { flash box positif } \\
\text { dan negatif }\end{array}$ & 1,16 & $1+46$ \\
\hline \multicolumn{2}{|l|}{ Rata-rata } & 1,14 & $1+28 \%$ \\
\hline
\end{tabular}

\section{Perhitungan Beban Kerja Operator dengan Workload Analysis (WLA)}

Perhitungan beban kerja adalah untuk mengetahui beban yang diterima oleh operator pada saat bekerja dengan performance rating dan allowance yang telah didapatkan, adapun perhitunggannya adalah:

$$
\begin{aligned}
\mathrm{BK}= & (\% \text { produktif } \times \text { performance rating }) \times \\
& (1+\text { allowance }) \\
\mathrm{BK}= & (93 \% \times 1,14) \times(1+28 \%) \\
\mathrm{BK}= & 1,36
\end{aligned}
$$

\section{Kebutuhan Tenaga Kerja Berdasarkan Beban Kerja}

Beban kerja yang diperoleh dari hasil sebelumnya adalah untuk operator Adin adalah 136\%. Dari hasil perhitungan kondisi awal operator (Operator 1) maka terlihat bahwa beban kerja yang diterima masih berat karena BK > $100 \%$. Untuk mengetahui total beban kerja pada stasiun pembuatan cetakan worm screw, maka total beban kerja yang didapat dari perhitungan operator adin $\times 2$ karena pada stasiun ini terdapat 2 operator yang bekerja dengan pekerjaan yang sama.

Total Beban Kerja $\quad=136 \% \times 2=272 \%$

\section{Analisa}

\section{Kondisi Awal}

Pada kondisi awal yaitu dengan 2 orang operator dan dengan total beban kerja sebesar $272 \%$.

Rata-rata beban kerja kondisi awal

$$
=\frac{2,72 \%}{2}=136 \%
$$

Dari hasil perhitungan kondisi awal dengan 2 operator maka terlihat bahwa beban kerja yang diterima masih berat karena BK > $100 \%$, oleh sebab itu maka akan dilakukan usulan penambahan beban kerja menjadi 3 orang dan 4 orang yang dibuktikan dengan perhitungan berikut.

Rata-rata beban kerja kondisi awal

$$
\begin{aligned}
& =\frac{272 \%}{3}=90,67 \% \\
& =\frac{272 \%}{4}=68 \%
\end{aligned}
$$

\section{Usulan Penambahan Tenaga Kerja}

Dari hasil perhitungan penambahan tenaga kerja maka didapatkan bahwa dengan adanya penambahan operator yang kondisi awal 2 orang operator menjadi 3 operator terlihat bahwa beban kerja yang diterima adalah sebesar $90,67 \%$ dimana kondisi ini $\mathrm{BK}<100 \%$ yang berarti beban kerja yang diterima dalam kategori 
ringan. Jika jumlah operator ditambah menjadi 4 operator maka beban kerja yang diterima adalah sebesar $68 \%$, maka akan banyak pekerja yang menganggur dalam proses produksi. Jadi, usulan jumlah operator yang disarankan adalah 3 orang.

\section{Kesimpulan}

Dari hasil penelitian yang telah dilakukan, maka diperoleh kesimpulan sebagai berikut:

1. Dari hasil perhitungan, maka waktu baku yang diperlukan oleh operator dalam menyelesaikan 1 unit cetakan worm screw adalah 20,5 menit.

2. Beban kerja fisik yang diterima oleh operator stasiun pembuatan cetakan worm screw di PT. Riau Logam Engineering adalah 136\% berada di range $>100 \%$ yang berarti bahwa beban kerja yang diterima oleh operator masih berada dalam kondisi berat, setelah dilakukan perbaikan dengan menambah 1 operator maka beban kerja fisik yang diterima oleh operator adalah $90,67 \%$ berada pada range $<100 \%$ yang berarti bahwa beban kerja fisik yang diterima dalam kondisi ringan.

\section{Daftar Pustaka}

Izzhati, Dwi Nurul. Implementasi Metode Work Sampling Guna Mengukur Produktivitas Tenaga Kerja di CV. Sinar Krom Semarang, Universitas Dian Nuswantoro Semarang, 2012.

Prabowo, R. E., 2010. Pengukuran Beban Kerja Pada Bagian Produksi Seperator Berdasarkan Metode Work Analysis (WLA). Surabaya: Universitas Pembangunan Nasional "Veteran".

Prakoso, Bagas. Pengaruh Orientasi Pasar, Inovasi dan Orientasi Pembelajaran Terhadap Kinerja Perusahaan Untuk Mencapai Keunggulan Bersaing (Studi Empiris Pada Industri Manufaktur di Semarang), 2005.

Ramadhan, Rahadian dkk. Analisa Beban Kerja Dengan Work Sampling Dan Nasa-Tlx Untuk Menentukan Jumlah Operator (Study Kasus:PT XYZ). Universitas Brawijaya, Malang, 2015.

Soleman, Aminah. Analisa Beban Kerja Ditinjau Dari Faktor Usia Dengan Pendekatan Recommended Weiht Limit (Studi Kasus Mahasiswa Unipati Soka), 2011.
Sutalaksana, Iftikar Z. Teknik Tata Cara Kerja. Universitas Teknologi Bandung, Bandung, 1979.

Umar, Akmal. Pengaruh Upah, Motivasi Kerja, dan Kepuasan Kerja Terhadap Kinerja Pekerja Pada Industri Manufaktur di Kota Semarang. Sekolah Tinggi Ilmu Manajemen Indonesia, 2011.

Wignjosoebroto, Sritomo. Studi Gerak dan Waktu. Jakarta : PT. Guna Widya,2008 